\title{
Magnetic Resonance Characterization of Ischemic Tissue Metabolism
}

\author{
Jerry S. Cheung ${ }^{1}$, Xiaoying Wang ${ }^{2}$, Phillip Zhe Sun*,1 \\ ${ }^{I}$ Athinoula A. Martinos Center for Biomedical Imaging, Department of Radiology, Massachusetts General Hospital and \\ Harvard Medical School, Charlestown, MA 02129, USA; ${ }^{2}$ Neuroprotection Research Laboratory, Department of \\ Neurology and Radiology, Massachusetts General Hospital and Harvard Medical School, Charlestown, MA 02129, \\ USA
}

\begin{abstract}
Magnetic resonance imaging (MRI) and spectroscopy (MRS) are versatile diagnostic techniques capable of characterizing the complex stroke pathophysiology, and hold great promise for guiding stroke treatment. Particularly, tissue viability and salvageability are closely associated with its metabolic status. Upon ischemia, ischemic tissue metabolism is disrupted including altered metabolism of glucose and oxygen, elevated lactate production/accumulation, tissue acidification and eventually, adenosine triphosphate (ATP) depletion and energy failure. Whereas metabolism impairment during ischemic stroke is complex, it may be monitored non-invasively with magnetic resonance (MR)-based techniques. Our current article provides a concise overview of stroke pathology, conventional and emerging imaging and spectroscopy techniques, and data analysis tools for characterizing ischemic tissue damage.
\end{abstract}

Keywords: MRI; MRS, cerebral ischemia, stroke; metabolism.

\section{INTRODUCTION}

Ischemic brain tissue damage mechanisms are complex, and have been categorized into pathophysiology, biochemistry, gene expression, cell signaling, pharmacology, and neuroimaging changes [1-3]. Magnetic resonance (MR)based techniques have been playing a vital role not only to assist our understanding of stroke pathology but also to help guide stroke patient management [4-10]. As such, it is important to define relevant pathophysiologic mechanisms in stroke as determined by molecular and functional neuroimaging, identify and prospectively validate surrogate imaging biomarkers of tissue injury for early prediction of tissue outcome, and ultimately guide individualized stroke treatment, both in experimental stroke models and translational clinical investigation [11-13]. Our article provides a concise overview of stroke pathology, conventional and emerging MRI and MRS techniques, and multi-parametric data analysis tools that characterize the hemodynamic, metabolic, structural impairments subsequent to ischemic injury.

\section{ISCHEMIC STROKE TISSUE DAMAGE}

Ischemic stroke occurs when a major cerebral artery becomes blocked, causing severe hypoperfusion to the brain. Blood clots are the most common cause of artery blockage and brain infarction. After ischemic stroke brain tissue ceases to function and latterly suffers irreversible injury possibly leading to death of the tissue, i.e., infarction. Upon ischemia, tissue becomes low in energy substrates including

*Address correspondence to this author at the Athinoula A. Martinos Center for Biomedical Imaging, Department of Radiology, MGH and Harvard Medical School, Rm 2301, $14913^{\text {th }}$ street, Charlestown, MA 02129, USA; Tel: 617-726-4060; Fax: 617-726-7422;

E-mail:pzhesun@nmr.mgh.harvard.edu glucose and oxygen, and resorts to anaerobic respiration. Anaerobic glycolysis, however, produces less adenosine triphosphate (ATP) yet releases lactic acid as a byproduct. Lactic acid is an irritant and at high concentration, could further disrupt tissue metabolism and potentially destroy cells [1]. The major cascade of neuronal injury and brain infarction after ischemic stroke is initiated when the energy production such as ATP fails, leading to failure of energydependent processes (such as ion pumping) that are vital for cell viability [14]. Another major cause of neuronal injury is the release of excitatory neurotransmitters such as glutamate. The extracellular glutamate concentration is normally kept low, powered by the concentration gradients of ions (mainly $\mathrm{Na}^{+}$) across the neuronal cell membrane. After stroke, the energy-dependent trans-membrane ion gradients run down, and glutamate transporters reverse their direction, releasing glutamate into the extracellular space. Glutamate acts on receptors in neuronal cells and therefore, produces an influx of calcium that activates enzymes that digest cellular proteins, lipids and nuclear materials. Calcium influx can also lead to the failure of mitochondria, which may cause further energy deterioration. Ischemia also induces production of free radicals and other reactive oxygen species, which may react with and subsequently damage a number of cellular and extracellular elements. In addition to injurious effects on brain cells, the loss of neurovascular structural integrity and functional coupling may also result in neurological dysfunction, a breakdown of the protective blood brain barrier (BBB) that contributes to cerebral edema, which can cause secondary progression of the brain injury $[3,15]$.

Emerging evidence suggests that ischemic brain damage is a dynamic process that evolves over time. The progression and the extent of ischemic injury are influenced by many factors, including age, severity and location of occlusion, 
state of collateral and systemic circulation, hematological and coagulation factors, body temperature and blood glucose level, etc [16]. Furthermore, acute ischemic tissue often suffers a gradient loss of perfusion, rather than complete and homogeneous ischemia of the entire occluded vessel supplying territory [10]. The key pathophysiological concept is the delineation of ischemic tissue into three operational compartments. Regions suffering the most severe hypoperfusion rapidly progress to irreversible damage and inevitably infarct, representing the ischemic core. The remaining hypoperfused tissue exhibits impairment of the normal blood flow autoregulatory mechanisms and can be pathophysiologically divided into two compartments, namely, salvageable tissue at risk of infarction 'penumbra' and mild ischemic tissue at no immediate risk of infarction 'oligaemia'[17]. The ischemic penumbra was originally described on electrophysiological basis as the tissue existing between the thresholds of electrical failure and ion pump failure [18]. In the ischemic penumbra, oxygen metabolism is preserved and thereby potentially salvageable. Its extent however, decreases over time due to gradual deterioration and as such, represents a key target for therapeutic intervention [19]. Whereas this course of events varies from patient to patient, it has been shown that ischemic penumbra may last for many hours after stroke onset [20]. Timely rescue of the penumbra, either by restoration of blood supply or interruption of the adverse metabolic or neurochemical cascades, is the basis of acute stroke therapy. The benign oligaemic tissue, on the other hand, suffers a mild degree of hypoperfusion with normal oxygen consumption and elevated cerebral blood volume (CBV) and oxygen extraction fraction (OEF), and is not at immediate risk of infarction. If the occlusion persists, however, secondary events such as systemic hypotension, intracranial hypertension or hyperglycaemia may topple this delicate balance and induce the oligaemic tissue to transform into penumbral state and eventually being recruited into the necrotic core [17].

\section{MRS CHARACTERIZATION OF ACUTE STROKE}

Magnetic resonance spectroscopy (MRS) is capable of studying cellular biochemistry and metabolism by measuring various cerebral metabolites, providing a noninvasive and sensitive means to assess acute ischemic stroke and its progression [21]. Studies of metabolites using proton $\left({ }^{1} \mathrm{H}\right)$ and phosphorus-31 $\left({ }^{31} \mathrm{P}\right)$ MRS have enormously contributed to our understanding of cellular metabolism and pathophysiologic processes of cerebral ischemia. Singlevoxel based MRS techniques such as point resolved spectroscopy (PRESS) or stimulated echo acquisition mode (STEAM) have been increasingly employed in stroke exams due to its widespread availability and reasonable acquisition time. Recently, there has been great interest in the development of magnetic resonance spectroscopic imaging (MRSI), which can provide information regarding the spatial distribution of metabolites after stroke [22-26] by means of metabolite maps [25], despite moderately longer acquisition time.

Among various metabolites detectable by ${ }^{1} \mathrm{H}$ MRS, increase in lactate $(1.33 \mathrm{ppm})$ is the most prominent feature of ischemic stroke. Lactate, produced as a metabolic endproduct of anaerobic glycolysis after the onset of ischemic insult, provides a sensitive means for detecting acute stroke $[27,28]$. In ${ }^{1} \mathrm{H}$ MR spectra obtained at short echo time, lactate signal overlaps with lipid peaks (0.9-1.4 ppm), rendering quantitative detection of lactate difficult. Due to the short $\mathrm{T}_{2}$ relaxation time of lipids, long echo time spectra can suppress the lipid signal and facilitate the measurement of lactate [29]. It is noteworthy that the signal of lactate modulates with echo time due to J-coupling [30], and the lactate doublet peaks are in phase and usually acquired at TE $=136$ (inverted) or $272 \mathrm{~ms}$. Apart from lactate, N-acetyl aspartate (NAA; $2.01 \mathrm{ppm}$ ) is found to decrease after onset of stroke and continues to decline with time in ischemic lesion [27, 28]. Being highly correlated with histological findings in animal studies, NAA signal decrease indicates neuronal loss or damage after cerebral ischemia [31, 32]. As such, NAA may serve as a metabolic marker in determining early tissue viability. The degree of ischemia and neuronal viability as determined by levels of lactate and NAA, respectively, during acute phase of ischemic stroke has been shown to correlate with the severity of ischemic insult and outcome $[33,34]$. Maniega et al. demonstrated that temporal evolutions of both lactate and NAA concentrations in stroke patients can provide useful insights into the dynamics of ischemic stroke [35]. Furthermore, it has been suggested that region with near normal NAA but elevated lactate level may represent salvageable ischemic penumbra in acute stroke [25, $36,37]$.

${ }^{31} \mathrm{P}$ MRS has been used to study energy states in ischemic stroke by assessing the high-energy phosphorus-containing moieties participating in energy metabolism, particularly ATP and phosphocreatine (PCr) [38-42]. During ischemia, $\mathrm{PCr}$ energy buffer decreases with the increase of inorganic phosphate $\left(\mathrm{P}_{\mathrm{i}}\right)$ in order to maintain ATP homeostasis, and ATP levels decreases once PCr buffer is depleted. In addition, ${ }^{31} \mathrm{P}$ MRS can provide information about intracellular acidosis by determining the difference in chemical shift between the $\mathrm{P}_{\mathrm{i}}$ and $\mathrm{PCr}$ peaks $(\delta)$ as $\mathrm{pH}=6.72$ $+\log ((\delta-3.27) /(5.69-\delta))[38,39,41,43]$.

\section{MRI CHARACTERIZATION OF ACUTE STROKE}

Commonly used stroke MRI methods include perfusion, diffusion and relaxation MRI. In addition, magnetization transfer (MT) and $\mathrm{pH}$-weighted amide proton chemical exchange saturation transfer (CEST) MRI are also being explored for stroke imaging. It is important to note that whereas computed tomography (CT) is the most utilized method while positron emission tomography (PET) provides more specific characterization of tissue metabolism and perfusion, MRI is widely used due to its multi-parametric diagnosis capability, relatively easy access and nonionization radiation $[8,11,13,44-46]$.

\subsection{Perfusion and Diffusion MRI}

Perfusion and diffusion MRI are most commonly used stroke imaging techniques, providing information about disrupted hemodynamic and cellular structural status [17, 4751]. Whereas MR angiogram can detect the location and severity of occlusion, the downstream tissue hemodynamic status can be better characterized with dynamic susceptibility contrast (DSC), dynamic contrast enhance (DCE) and arterial spin labeling (ASL) techniques, providing quantitative parameters such as cerebral blood flow (CBF), 
volume (CBV) and mean transit time (MTT), etc [52, 53]. Particularly, ASL MRI employs arterial water as an endogenous tracer, and is completely non-invasive and very popular in pre-clinical studies $[54,55]$. Nevertheless, quantitative perfusion imaging requires assessment of the hemodynamic system such as the arterial input function (AIF) and often assumes intact blood brain barrier (BBB), which may be somewhat oversimplified. Recently, an endogenous imaging technique dubbed modulation of tissue and vessel (MOTIVE) has been proposed to quantify arterial blood volume, which may augment contrast enhanced perfusion MRI [56]. On the other hand, cerebral perfusion is complex and depends on the physiological states and anatomy. Particularly, it has been found that brain white matter (WM) and grey matter (GM) have different perfusion thresholds for ischemia, and a tissue-specific rather than whole brain threshold has been suggested for better prediction of infarction [57].

Diffusion MRI measures the random Brownian motion of water molecules, and has been regarded as one of the most sensitive MRI parameters for imaging stroke [58-63]. It detects ischemic lesion within minutes after hypoperfusion, significantly earlier than the conventional relaxation-based methods [64]. In fact, the development of diffusion-weighted imaging (DWI) has transformed the use of MRI for acute stroke imaging. Specifically, diffusion MRI detects severely injured ischemic tissue while the hypoperfused tissue can be identified with perfusion MRI, leading to the postulation that the mismatch between perfusion and diffusion lesions represents salvageable ischemic tissue $[34,65,66]$. While on the other hand, diffusion lesion, if treated promptly, is reversible yet its long term outcome is rather variable [6769]. In addition, metabolic impairment within the diffusion lesion has been found to be non-uniform, which may partially explain its heterogeneous outcome [68, 70]. Therefore, the perfusion/diffusion mismatch provides a very useful yet somewhat crude estimation of ischemic penumbra and new surrogate imaging biomarkers are urgently needed to better delineate the heterogeneous ischemic tissue damage $[71,72]$.

\section{2. $T_{2}$ and $T_{2} * M R I$}

$\mathrm{T}_{2}$ is a fundamental MRI parameter, sensitive to vasogenic edema and increased water content, and significant $T_{2}$ prolongation often suggests irreversible tissue damage [73-75]. $T_{2}$ increase in ischemic lesion has also been suggested to be associated with change in magnetization transfer between mobile and immobile proton pools due to structural water alteration [76-78], in which reduced bound water fraction in ischemic tissue leads to $T_{2}$ prolongation without significant change in water content. Being highly correlated with established histological and enzymatic techniques, volume with elevated $\mathrm{T}_{2}$ in late stages has been widely used to estimate final infarct size noninvasively [79, 80]. In addition, Siemonsen et al. showed that $T_{2}$ difference between infarct core and contralateral brain tissue was highly correlated with the time from symptom onset, allowing estimation of lesion age which is usually unclear clinically [81]. It should be noted that $T_{2}$ has been shown to decrease moderately during the initial period of ischemia (hyperacute phase) in which concentration of deoxyhemoglobin increases in areas of hypoperfusion, leading to an increased amount of spin dephasing of diffusing protons [82-84]. Moreover, transient $T_{2}$ normalization during the subacute stage of ischemic stroke has been reported, likely due to transient normalization of water content [85].

$\mathrm{T}_{2}{ }^{*}$ is another informative MRI parameter that is sensitive to the local blood oxygenation level, known as blood oxygenation level-dependent (BOLD) effect and widely used in functional MRI (fMRI) [86, 87]. Signal change due to the BOLD effect has been observed in acute ischemic stroke using $\mathrm{T}_{2}{ }^{*}$-weighted imaging [88-91]. It has been shown that regions of viable yet ischemic brain tissue exhibit decreased $\mathrm{T}_{2}{ }^{*}$ and $\mathrm{T}_{2}{ }^{\prime}$ (corrected with spin-spin effects) as a result of an increase in regional deoxyhemoglobin concentration caused by elevated oxygen extraction fraction (OEF) and hypoperfusion [90, 91]. Moreover, $\mathrm{T}_{2} *$ signal change has been used to detect changes in cerebrovascular reactivity during and after transient ischemia to assess tissue damage in animals. Ono et al. illustrated that impaired $\mathrm{CO}_{2}$ reactivity after transient ischemia revealed irreversible ischemic damage, whereas recovered $\mathrm{CO}_{2}$ reactivity during reperfusion indicated absence of pathological damage [92]. Furthermore, Santosh et al. demonstrated that in permanent middle cerebral artery occlusion (MCAO) model, areas with increased $\mathrm{T}_{2} *$ signal indicate oxygen utilization, which is viable and metabolically active, while areas without significant $\mathrm{T}_{2}$ * signal change suggest severely disrupted metabolism and are likely severely damaged [93].

\section{3. pH-weighted MRI}

Whereas tissue $\mathrm{pH}$ can be assessed by ${ }^{31} \mathrm{P} \mathrm{MRS}$ and to some extent, lactate MRS, their spatiotemporal resolution is limited and not suitable for routine examination of acute stroke patients [94-97]. To address this, $\mathrm{pH}$ imaging has been developed, based on the principle of chemical exchange saturation transfer (CEST) MRI [98]. CEST MRI is an emerging MRI method capable of detecting dilute labile proton groups and local $\mathrm{pH}$ [99-104]. In particular, amide proton transfer (APT) MRI, a specific form of CEST MRI that probes $\mathrm{pH}$-dependent amide proton exchange from endogenous mobile proteins and polypeptides, offers a noninvasive $\mathrm{pH}$ imaging technique for characterizing ischemic acidosis $[102,105,106]$. Noteworthily, the sensitivity of $\mathrm{pH}$ MRI is significantly higher than MRS-based methods (e.g., lactate and $\left.{ }^{31} \mathrm{P} \mathrm{MRI}\right)$, and permits $\mathrm{pH}$ mapping at spatiotemporal resolution comparable to that of ASL MRI [103, 107].

Both numerical simulation and empirical solutions have been developed to guide optimization and quantification of CEST MRI since the pioneering work of Balaban et al. [108112]. pH-weighted APT MRI has been translated to image ischemic acidosis, an early marker of impaired tissue metabolism [113-115]. Specifically, Sun et al. established a dual 2-pool mathematical model to describe in vivo APT MRI during acute stroke, and quantified the endogenous mobile amide proton concentration and exchange rate [109, 116]. In addition, $\mathrm{pH}$-weighted APT MRI lesion detects not only severely injured ischemic lesion that shows diffusion abnormality, but also ischemic lesions with $\mathrm{T}_{2}$ hypointensity, a surrogate marker for altered oxygen metabolism [91, 93]. Moreover, it has been suggested that $\mathrm{pH}$-weighted APT MRI 
can better predict stroke outcome, in complementary to the commonly used perfusion and diffusion MRI [117]. Recently, Jokivarsi et al. also showed that $\mathrm{pH}$-weighted APT contrast correlates with lactate MRS [118]. In addition, we have demonstrated that the correlation between endogenous APT contrast and lactate content can be enhanced with $\mathrm{T}_{1^{-}}$ normalized APT MRI, consistent with the fact that APT/CEST contrast approximately scales with $T_{1}$. Nevertheless, in vivo APT MRI is complex. In addition to pH-weighted APT contrast, it is also susceptible to concomitant RF irradiation effects, slightly asymmetric semisolid macromolecular magnetization transfer (MT) and nuclear overhauser effect (NOE), which have to be further investigated for quantitative $\mathrm{pH}$ imaging [119-121]. Noteworthily, $\mathrm{pH}$ MRI may be suitable for studying transient ischemic attack (TIA). For instance, Sicard et al. showed that despite full recovery of perfusion and diffusion images, animals with transient MCAO (tMCAO) showed delayed normalization in behavior and fMRI, suggesting prolonged neuronal damage [122]. Similarly, Bisschops et al. reported that although the neurological deficits of TIA patients are transient, their metabolic changes are present days after the onset of symptoms, and not limited to the symptomatic hemisphere [123]. Therefore, multi-parametric characterization of tissue metabolic status such as tissue $\mathrm{pH}$ and lactate may provide new insights into TIA. While on the other hand, whereas endogenous APT MRI has been shown capable of detecting ischemic acidosis $24 \mathrm{hr}$ after MCAO, its contrast is very complex due to proteolysis, change in tissue temperature and relaxation times $[106,117,124]$. To address this limitation, additional mathematical modeling is needed to delineate tissue $\mathrm{pH}$ from the confounding amide proton concentration effect [102, 125].

\subsection{Sodium MRI}

Sodium (Na) MRI offers a very promising imaging technique to examine tissue viability [126]. Well regulated sodium balance is vital for cell viability: the cytoplasm has low sodium yet high potassium concentration, in contrast to interstitial space. The regulation of sodium and potassium depends on ATP dependent active transporters, which dysfunctions upon membrane depolarization during ischemia [127, 128]. Subsequently, cytoplasm sodium level increases significantly, which may serve as a specific marker for metabolic disruption and cell viability [129]. Whereas $T_{2}$ of sodium MR signal is very short, twisted projection imaging (TPI) has been developed that permits three-dimensional acquisition of sodium imaging in vivo [130]. In addition, intracellular sodium can be differentiated from interstitial space using double quantum filter, which may further improve the specificity of sodium imaging. Moreover, it has been shown that the total sodium concentration may serve as a tissue clock for estimating stroke onset time, aiding stroke treatment $[131,132]$.

\section{MULTI-PARAMETRIC IMAGE ANALYSIS}

Due to the dynamic nature of ischemic tissue damage, a single MRI parameter often has its own time window to reveal the abnormality, and thus may not fully characterize the ischemic tissue injury [133]. For instance, ADC declines rapidly within minutes of ischemic stroke, but it pseudonormalizes and even rises above the normal range in latter stages [68]. Therefore, the multi-parametric MRI analysis is necessary to assess the heterogeneous ischemic tissue damage $[13,134]$. Specifically, methods including generalized linear model (GLM), K-means, fuzzy c-means, and interactive self-organizing data analysis technique algorithm (ISODATA) segmentation with multi-parametric MRI have been suggested for ischemic tissue classification $[44,135,136]$. In particular, ISODATA is an unsupervised segmentation algorithm based on cluster analysis which can recognize structures within a data set and automatically determine the number of clusters [137]. Multiple tissue signatures can be segmented from the data set by ISODATA, generating a theme map that reflects different tissue clusters [138]. Studies have shown that ISODATA technique can accurately define the ischemic region which was well correlated with histologically determined lesion at different stages after stroke [136, 139], and ISODATA lesion volume at acute stage has strong correlation with stroke outcome $[138,140]$. Increasing the dimensionality of the ISODATA model by incorporating additional images has been shown to better demarcate tissue clusters [139, 141]. Moreover, the heterogeneity within the ischemic lesion in the ISODATA theme map has been suggested to indicate heterogeneous tissue damage [142]. Furthermore, Shen et al. showed that employing statistical algorithm following ISODATA tissue clustering can help improve the prediction of the ischemic tissue outcome in animal models [143, 144]. Specifically, a training data set was used to derive the probability profiles of tissue fate pixel-by-pixel, which were then applied to generate maps of risk of subsequent infarction. Such a predictive approach has been shown to improve the predication in transient stroke by taking into account of the regional susceptibility to infarction [144]. More recently, predictive algorithm based on artificial neural network has also been developed for prediction of ischemic tissue fate based on multiparametric MRI data [145]. These predictive models, if fully developed, may greatly aid clinical decision making in the treatment of acute stroke by providing objective predictions of ischemic tissue fates.

\section{CONCLUSIONS AND PROSPECTS}

MRI and MRS techniques have greatly improved our understanding of stroke pathophysiology. In addition, emerging MR techniques are being developed to capture new facets of ischemic tissue damage with enhanced sensitivity and specificity. Such a breadth of information can be characterized with multi-parametric analysis tools for improved tissue classification. Most importantly, further development and validation of MR techniques and image analysis tools may help establish imaging-based outcome prediction algorithms and ultimately, guide individualized stroke treatment.

\section{ACKNOWLEDGEMENT}

This study was supported in part by grants from AHA/SDG 0835384N, NIH/NIBIB 1K01EB009771 and NIH/1R21NS061119.

\section{REFERENCES}

[1] Back T, Hemmen T, Schuler OG. Lesion evolution in cerebral ischemia. J Neurol 2004; 251: 388-97. 
[2] Fisher M, Henninger N. Translational research in stroke: taking advances in the pathophysiology and treatment of stroke from the experimental setting to clinical trials. Curr Neurol Neurosci Rep 2007; 7: 35-41.

[3] Lo EH. Experimental models, neurovascular mechanisms and translational issues in stroke research. Br J Pharmacol 2008; 153 Suppl 1: S396-405.

[4] Schlaug G, Benfield A, Baird AE, et al. The ischemic penumbra: Operationally defined by diffusion and perfusion MRI. Neurology 1999; 53: 1528-37.

[5] Warach S. Thrombolysis in stroke beyond three hours: Targeting patients with diffusion and perfusion MRI. Ann Neurol 2002; 51: 11-3.

[6] Davis S, Donnan G, Butcher K, Parsons M. Selection of thrombolytic therapy beyond $3 \mathrm{~h}$ using magnetic resonance imaging. Curr Opin Neurol 2005; 18: 47-52.

[7] Gonzalez RG. Imaging-guided acute ischemic stroke therapy: From "time is brain" to "physiology is brain". Am J Neuroradiol 2006; 27: 728-35.

[8] Albers G, Thijs VN, Wechsler L, et al. Magnetic resonance imaging profiles predict clinical response to early reperfusion: The diffusion and perfusion imaging evaluation for understanding stroke evolution (DEFUSE) study. Ann Neurol 2006; 60: 508-17.

[9] Hacke W, Kaste M, Bluhmki E, et al. Thrombolysis with alteplase 3 to 4.5 hours after acute ischemic stroke. N Engl J Med 2008; 359 : 1317-29.

[10] Kloska SP, Wintermark M, Engelhorn T, Fiebach JB. Acute stroke magnetic resonance imaging: current status and future perspective. Neuroradiology 2010 52: 189-201.

[11] Schaefer PW, Ozsunar Y, He J, et al. Assessing Tissue Viability with MR Diffusion and Perfusion Imaging. Am J Neuroradiol 2003; 24: 436-43.

[12] Weber R, Ramos-Cabrer P, Hoehn M. Present status of Magnetic resonance imaging and spectroscopy in animal stroke models. J Cereb Blood Flow Metab 2005; 26: 591-604.

[13] Farr TD, Wegener S. Use of magnetic resonance imaging to predict outcome after stroke: a review of experimental and clinical evidence. J Cereb Blood Flow Metab 2010; 30: 703-17.

[14] Taoufik E, Probert L. Ischemic neuronal damage. Curr Pharm Des 2008; 14: 3565-73.

[15] Lee SR, Wang X, Tsuji K, Lo EH. Extracellular proteolytic pathophysiology in the neurovascular unit after stroke. Neurol Res 2004; 26: 854-61.

[16] Liebeskind DS. Imaging the future of stroke: I. Ischemia. Ann Neurol 2009; 66: 574-90.

[17] Muir KW, Buchan A, von Kummer R, Rother J, Baron JC. Imaging of acute stroke. Lancet Neurol 2006; 5: 755-68.

[18] Astrup J, Siesjo BK, Symon L. Thresholds in cerebral ischemia the ischemic penumbra. Stroke 1981; 12: 723-5.

[19] Lo EH. A new penumbra: transitioning from injury into repair after stroke. Nat Med 2008; 14: 497-500.

[20] Baron JC, Marchal G. Ischemic core and penumbra in human stroke. Stroke 1999; 30: 1150-3.

[21] Saunders DE. MR spectroscopy in stroke. British Medical Bulletin 2000; 56: 334-45.

[22] Sasahira M, Uchimura K, Yatsushiro K, Fujimoto T, Asakura T. Early detection of cerebral infarction by $31 \mathrm{P}$ spectroscopic imaging. Neuroradiology 1990; 32: 43-6.

[23] Ford CC, Griffey RH, Matwiyoff NA, Rosenberg GA. Multivoxel 1H-MRS of stroke. Neurology 1992; 42: 1408-12.

[24] Petroff OA, Graham GD, Blamire AM, et al. Spectroscopic imaging of stroke in humans: histopathology correlates of spectral changes. Neurology 1992; 42: 1349-54.

[25] Gillard JH, Barker PB, van Zijl PC, Bryan RN, Oppenheimer SM. Proton MR spectroscopy in acute middle cerebral artery stroke. Am J Neuroradiol 1996; 17: 873-86.

[26] van der Zijden JP, van Eijsden P, de Graaf RA, Dijkhuizen RM. 1H/13C MR spectroscopic imaging of regionally specific metabolic alterations after experimental stroke. Brain 2008; 131: 2209-19.

[27] Berkelbach van der Sprenkel JW, Luyten PR, van Rijen PC, Tulleken CA, den Hollander JA. Cerebral lactate detected by regional proton magnetic resonance spectroscopy in a patient with cerebral infarction. Stroke 1988; 19: 1556-60.

[28] Bruhn H, Frahm J, Gyngell ML, et al. Cerebral metabolism in man after acute stroke: new observations using localized proton NMR spectroscopy. Magn Reson Med 1989; 9: 126-31.
[29] Harada K, Honmou O, Liu H, et al. Magnetic resonance lactate and lipid signals in rat brain after middle cerebral artery occlusion model. Brain Res 2007; 1134: 206-13.

[30] Williams SR, Proctor E, Allen K, Gadian DG, Crockard HA. Quantitative estimation of lactate in the brain by $1 \mathrm{H}$ NMR. Magn Reson Med 1988; 7: 425-31.

[31] Sager TN, Laursen H, Hansen AJ. Changes in N-acetyl-aspartate content during focal and global brain ischemia of the rat. J Cereb Blood Flow Metab 1995; 15: 639-46.

[32] Sager TN, Hansen AJ, Laursen H. Correlation between Nacetylaspartate levels and histopathologic changes in cortical infarcts of mice after middle cerebral artery occlusion. J Cereb Blood Flow Metab 2000; 20: 780-8.

[33] Pierce AR, Lo EH, Mandeville JB, et al. MRI measurements of water diffusion and cerebral perfusion: their relationship in a rat model of focal cerebral ischemia. J Cereb Blood Flow Metab 1997; 17: 183-90.

[34] Parsons MW, Barber PA, Chalk J, et al. Diffusion- and perfusionweighted MRI response to thrombolysis in stroke. Ann Neurol 2002; 51: 28-37.

[35] Munoz Maniega S, Cvoro V, Chappell FM, et al. Changes in NAA and lactate following ischemic stroke: a serial MR spectroscopic imaging study. Neurology 2008; 71: 1993-9.

[36] Barker PB, Gillard JH, van Zijl PC, et al. Acute stroke: evaluation with serial proton MR spectroscopic imaging. Radiology 1994; 192: 723-32.

[37] Cvoro V, Marshall I, Armitage PA, et al. MR diffusion and perfusion parameters: relationship to metabolites in acute ischaemic stroke. J Neurol Neurosurg Psychiatry 2010; 81: 185-91.

[38] Naruse S, Takada S, Koizuka I, Watari H. In vivo 31P NMR studies on experimental cerebral infarction. Jpn J Physiol 1983; 33: 19-28.

[39] Komatsumoto S, Nioka S, Greenberg JH, et al. Cerebral energy metabolism measured in vivo by $31 \mathrm{P}-\mathrm{NMR}$ in middle cerebral artery occlusion in the cat--relation to severity of stroke. J Cereb Blood Flow Metab 1987; 7: 557-62.

[40] Germano IM, Pitts LH, Berry I, De Armond SJ. High energy phosphate metabolism in experimental permanent focal cerebral ischemia: an in vivo $31 \mathrm{P}$ magnetic resonance spectroscopy study. $\mathrm{J}$ Cereb Blood Flow Metab 1988; 8: 24-31.

[41] Germano IM, Pitts LH, Berry I, Moseley M. Magnetic resonance imaging and $31 \mathrm{P}$ magnetic resonance spectroscopy for evaluating focal cerebral ischemia. J Neurosurg 1989; 70: 612-8.

[42] Smith C, Thomas G, Kryscio R, Markesbery W. 31P spectroscopy in experimental embolic stroke: correlation with infarct size. NMR Biomed 1990; 3: 259-64.

[43] Moon RB, Richards JH. Determination of intracellular $\mathrm{pH}$ by ${ }^{31} \mathrm{P}$ magnetic resonance. J Biol Chem 1973; 248: 7276-8.

[44] Wu O, Koroshetz WJ, Ostergaard L, et al. Predicting Tissue Outcome in Acute Human Cerebral Ischemia Using Combined Diffusion- and Perfusion-Weighted MR Imaging. Stroke 2001; 32: 933-42.

[45] Kidwell C, Hsia A. Imaging of the brain and cerebral vasculature in patients with suspected stroke: advantages and disadvantages of CT and MRI. Curr Neurol Neurosci Rep 2006; 6: 9-16.

[46] Chalela JA, Kidwell CS, Nentwich LM, et al. Magnetic resonance imaging and computed tomography in emergency assessment of patients with suspected acute stroke: a prospective comparison. The Lancet 2007; 369: 293-8.

[47] Guadagno JV, Calautti C, Baron JC. Progress in imaging stroke: emerging clinical applications. Br Med Bull 2003; 65: 145-57.

[48] Heiss WD, Sobesky J, Hesselmann V. Identifying thresholds for penumbra and irreversible tissue damage. Stroke 2004; 35: 2671-4.

[49] Endo H, Inoue T, Ogasawara K, et al. Quantitative Assessment of Cerebral Hemodynamics Using Perfusion-Weighted MRI in Patients With Major Cerebral Artery Occlusive Disease: Comparison With Positron Emission Tomography. Stroke 2006; 37: 388-92.

[50] Takasawa M, Jones PS, Guadagno JV, et al. How Reliable Is Perfusion MR in Acute Stroke?: Validation and Determination of the Penumbra Threshold Against Quantitative PET. Stroke 2008; 39: 870-7.

[51] Zaro-Weber O, Moeller-Hartmann W, Heiss W-D, Sobesky J. The Performance of MRI-Based Cerebral Blood Flow Measurements in Acute and Subacute Stroke Compared With 15O-Water Positron Emission Tomography: Identification of Penumbral Flow. Stroke 2009; 40: 2413-21. 
[52] Barbier EL, Lamalle L, Décorps M. Methodology of brain perfusion imaging. J Magn Reson Imag 2001; 13: 496-520.

[53] Wu O, Ostergaard L, Sorensen AG. Technical Aspects of Perfusion-Weighted Imaging. Neuroimaging clinics of North America 2005; 15: 623-37.

[54] Williams D, Detre J, Leigh J, Koretsky A. Magnetic resonance imaging of perfusion using spin inversion of arterial water. Proc Natl Acad Sci 1992; 89: 212-6.

[55] Alsop DC, Detre JA. Multisection cerebral blood flow MR imaging with continuous arterial spin labeling. Radiology 1998; 208: 410-6.

[56] Kim T, Kim SG. Quantification of cerebral arterial blood volume and cerebral blood flow using MRI with modulation of tissue and vessel (MOTIVE) signals. Magn Reson Med 2005; 54: 333-42.

[57] Bristow MS, Simon JE, Brown RA, et al. MR perfusion and diffusion in acute ischemic stroke: human gray and white matter have different thresholds for infarction. J Cereb Blood Flow Metab 2005; 25 : 1280-7.

[58] Tanner JE. Use of the Stimulated Echo in NMR Diffusion Studies. J Chemical Phys 1970; 52: 2523-6.

[59] Moseley M, Kucharczyk J, Mintorovitch J, et al. Diffusionweighted MR imaging of acute stroke: correlation with T2weighted and magnetic susceptibility-enhanced MR imaging in cats. Am J Neuroradiol 1990; 11: 423-9.

[60] Warach S, Chien D, Li W, Ronthal M, Edelman R. Fast magnetic resonance diffusion-weighted imaging of acute human stroke. Neurology 1992; 42: 1717-23.

[61] Back T H-BM, Kohno K, Hossmann KA. Diffusion nuclear magnetic resonance imaging in experimental stroke. Correlation with cerebral metabolites. Stroke 1994; 25: 494-500.

[62] Hossmann K, Fischer M, Bockhorst K, Hoehn-Berlage M. NMR imaging of the apparent diffusion coefficient (ADC) for the evaluation of metabolic suppression and recovery after prolonged cerebral ischemia. J Cereb Blood Flow Metab 1994; 14: 723-31.

[63] Kohno K, Hoehn-Berlage M, Mies G, Back T, Hossmann K-A. Relationship between diffusion-weighted MR images, cerebral blood flow, and energy state in experimental brain infarction. Magnetic Reson Imaging 1995; 13: 73-80.

[64] Moseley M, Cohen Y, Mintorovitch J, et al. Early detection of regional cerebral ischemia in cats: comparison of diffusion- and T2-weighted MRI and spectroscopy. Magn Reson Med 1990; 14: 330-46.

[65] Albers GW. Expanding the window for thrombolytic therapy in acute stroke. The potential role of acute MRI for patient selection. Stroke 1999; 30: 2230-7.

[66] Neumann-Haefelin T, Wittsack HJ, Wenserski F, et al. Diffusionand perfusion-weighted MRI. The DWI/PWI mismatch region in acute stroke. Stroke 1999; 30: 1591-7.

[67] Ringer TM, Neumann-Haefelin T, Sobel RA, Moseley ME, Yenari MA. Reversal of early diffusion-weighted magnetic resonance imaging abnormalities does not necessarily reflect tissue salvage in experimental cerebral ischemia. Stroke 2001; 32: 2362-9.

[68] Fiehler J, Foth M, Kucinski T, et al. Severe ADC decreases do not predict irreversible tissue damage in humans. Stroke 2002; 33: 7986.

[69] Kidwell CS, Alger JR, Saver JL. Beyond mismatch: evolving paradigms in imaging the ischemic penumbra with multimodal magnetic resonance imaging. Stroke 2003; 34: 2729-35.

[70] Nicoli F, Lefur Y, Denis B, et al. Metabolic Counterpart of Decreased Apparent Diffusion Coefficient During Hyperacute Ischemic Stroke: A Brain Proton Magnetic Resonance Spectroscopic Imaging Study. Stroke 2003; 34: 82-7.

[71] Sorensen AG. Apparently, Diffusion Coefficient Value and Stroke Treatment Remains Mysterious. Am J Neuroradiol 2002; 23: 1778 .

[72] Sobesky J, Weber OZ, Lehnhardt F-G, et al. Does the Mismatch Match the Penumbra?: Magnetic Resonance Imaging and Positron Emission Tomography in Early Ischemic Stroke. Stroke 2005; 36: 980-5.

[73] Buonanno FS, Pykett IL, Brady TJ, et al. Proton NMR imaging in experimental ischemic infarction. Stroke 1983; 14: 178-84.

[74] Mano I, Levy RM, Crooks LE, Hosobuchi Y. Proton nuclear magnetic resonance imaging of acute experimental cerebral ischemia. Invest Radiol 1983; 18: 345-51.

[75] Loubinoux I, Volk A, Borredon J, et al. Spreading of vasogenic edema and cytotoxic edema assessed by quantitative diffusion and
T2 magnetic resonance imaging. Stroke 1997; 28: 419-26; discussion 26-7.

[76] Knight RA, Ordidge RJ, Helpern JA, et al. Temporal evolution of ischemic damage in rat brain measured by proton nuclear magnetic resonance imaging. Stroke 1991; 22: 802-8.

[77] Ordidge RJ, Helpern JA, Knight RA, Qing ZX, Welch KM. Investigation of cerebral ischemia using magnetization transfer contrast (MTC) MR imaging. Magn Reson Imaging 1991; 9: 895902.

[78] Lin SP, Schmidt RE, McKinstry RC, Ackerman JJ, Neil JJ. Investigation of mechanisms underlying transient $\mathrm{T} 2$ normalization in longitudinal studies of ischemic stroke. J Magn Reson Imaging 2002; 15: 130-6.

[79] Bose B, Jones SC, Lorig R, et al. Evolving focal cerebral ischemia in cats: spatial correlation of nuclear magnetic resonance imaging, cerebral blood flow, tetrazolium staining, and histopathology. Stroke 1988; 19: 28-37.

[80] Palmer GC, Peeling J, Corbett D, Del Bigio MR, Hudzik TJ. T2weighted MRI correlates with long-term histopathology, neurology scores, and skilled motor behavior in a rat stroke model. Ann NY Acad Sci 2001; 939: 283-96.

[81] Siemonsen S, Mouridsen K, Holst B, et al. Quantitative t2 values predict time from symptom onset in acute stroke patients. Stroke 2009; 40: 1612-6.

[82] Quast MJ, Huang NC, Hillman GR, Kent TA. The evolution of acute stroke recorded by multimodal magnetic resonance imaging. Magn Reson Imaging 1993; 11: 465-71.

[83] Grohn OH, Lukkarinen JA, Oja JM, et al. Noninvasive detection of cerebral hypoperfusion and reversible ischemia from reductions in the magnetic resonance imaging relaxation time, T2. J Cereb Blood Flow Metab 1998; 18: 911-20.

[84] Calamante F, Lythgoe MF, Pell GS, et al. Early changes in water diffusion, perfusion, T1, and T2 during focal cerebral ischemia in the rat studied at $8.5 \mathrm{~T}$. Magn Reson Med 1999; 41: 479-85.

[85] Wegener S, Weber R, Ramos-Cabrer P, et al. Temporal profile of T2-weighted MRI distinguishes between pannecrosis and selective neuronal death after transient focal cerebral ischemia in the rat. $J$ Cereb Blood Flow Metab 2005; 26: 38-47.

[86] Ogawa S, Lee TM, Kay AR, Tank DW. Brain magnetic resonance imaging with contrast dependent on blood oxygenation. Proc Natl Acad Sci USA 1990; 87: 9868-72.

[87] Ogawa S, Lee TM, Nayak AS, Glynn P. Oxygenation-sensitive contrast in magnetic resonance image of rodent brain at high magnetic fields. Magn Reson Med 1990; 14: 68-78.

[88] De Crespigny AJ, Wendland MF, Derugin N, Kozniewska E, Moseley ME. Real-time observation of transient focal ischemia and hyperemia in cat brain. Magn Reson Med 1992; 27: 391-7.

[89] Roussel SA, van Bruggen N, King MD, Gadian DG. Identification of collaterally perfused areas following focal cerebral ischemia in the rat by comparison of gradient echo and diffusion-weighted MRI. J Cereb Blood Flow Metab 1995; 15: 578-86.

[90] Tamura H, Hatazawa J, Toyoshima H, Shimosegawa E, Okudera T. Detection of deoxygenation-related signal change in acute ischemic stroke patients by $\mathrm{T} 2 *$-weighted magnetic resonance imaging. Stroke 2002; 33: 967-71.

[91] Geisler BS, Brandhoff F, Fiehler J, et al. Blood-oxygen-leveldependent MRI allows metabolic description of tissue at risk in acute stroke patients. Stroke 2006; 37: 1778-84.

[92] Ono Y, Morikawa S, Inubushi T, Shimizu H, Yoshimoto T. T2*weighted magnetic resonance imaging of cerebrovascular reactivity in rat reversible focal cerebral ischemia. Brain Res 1997; 744: 207 15 .

[93] Santosh C, Brennan D, McCabe C, et al. Potential use of oxygen as a metabolic biosensor in combination with $\mathrm{T} 2 *$-weighted MRI to define the ischemic penumbra. J Cereb Blood Flow Metab 2008; 28: 1742-53.

[94] Paschen W, Djuricic B, Mies G, Schmidt-Kastner R, Linn F. Lactate and $\mathrm{pH}$ in the brain: association and dissociation in different pathophysiological states. J Neurochem 1987; 48: 154-9.

[95] Allen K, Busza A, Crockard H, et al. Acute cerebral ischaemia: concurrent changes in cerebral blood flow, energy metabolites, $\mathrm{pH}$, and lactate measured with hydrogen clearance and $31 \mathrm{P}$ and $1 \mathrm{H}$ nuclear magnetic resonance spectroscopy. III. Changes following ischaemia. J Cereb Blood Flow Metab 1988; 8: 816-21. 
[96] Katsura K, Asplund B, Ekholm A, Siesjö B. Extra- and intracellular $\mathrm{pH}$ in the brain during ischaemia, related to tissue lactate content in normo- and hypercapnic rats. Eur J Neurosci 1992; 4: 166-76.

[97] Gillies RJ, Raghunand N, Garcia-Martin ML, Gatenby RA. pH imaging. A review of $\mathrm{pH}$ measurement methods and applications in cancers. IEEE Eng Med Biol Mag 2004; 23: 57-64.

[98] Ward KM, Aletras AH, Balaban RS. A new class of contrast agents for MRI based on proton chemical exchange dependent saturation transfer (CEST). J Magn Reson 2000; 143: 79-87.

[99] Mori S, Eleff SM, Pilatus U, Mori N, van Zijl PCM. Proton NMR spectroscopy of solvent-saturable resonance: a new approach to study pH effects in situ. Magn Reson Med 1998; 40: 36-42.

[100] Ward KM, Balaban RS. Determination of $\mathrm{pH}$ using water protons and chemical exchange dependent saturation transfer (CEST). Magn Reson Med 2000; 44: 799-802.

[101] Zhou J, van Zijl PCM. Chemical Exchange Saturation Transfer Imaging. Prog Nucl Magn Reson Spectrosc 2006; 48: 109-36.

[102] Sun PZ, Sorensen AG. Imaging pH using the Chemical Exchange Saturation Transfer (CEST) MRI: Correction of Concomitant RF Irradiation Effects to Quantify CEST MRI for Chemical Exchange Rate and pH. Magn Reson Med 2008; 60: 390-7.

[103] Sun PZ, Murata Y, Lu J, et al. Relaxation-compensated fast multislice amide proton transfer (APT) imaging of acute ischemic stroke. Magn Reson Med 2008; 59: 1175-82.

[104] Terreno E, Castelli D, Aime S. Encoding the frequency dependence in MRI contrast media: the emerging class of CEST agents. Contrast Media Mol Imaging 2010; 5: 78-98.

[105] Wuthrich K, Wagner G. Nuclear magnetic resonance of labile protons in the basic pancreatic trypsin inhibitor. Journal of Molecul Biol 1979; 130: 1-18.

[106] Zhou J, Payen JF, Wilson DA, Traystman RJ, van Zijl PC. Using the amide proton signals of intracellular proteins and peptides to detect $\mathrm{pH}$ effects in MRI. Nat Med 2003; 9: 1085-90.

[107] Sun PZ, Cheung JS, Wang E, Benner T, Sorensen AG. Fast multislice pH-weighted chemical exchange saturation transfer (CEST) MRI with unevenly segmented RF irradiation. Magn Reson Med 2010; in press.

[108] Zhou J, Wilson DA, Sun PZ, Klaus JA, van Zijl PCM. Quantitative description of proton exchange processes between water and endogenous and exogenous agents for WEX, CEST, and APT experiments. Magn Reson Med 2004; 51: 945-52.

[109] Sun PZ, van Zijl PCM, Zhou J. Optimization of the irradiation power in chemical exchange dependent saturation transfer experiments. J Magn Reson 2005; 175: 193-200.

[110] Woessner DE, Zhang S, Merritt ME, Sherry AD. Numerical solution of the Bloch equations provides insights into the optimum design of PARACEST agents for MRI. Magn Reson Med 2005; 53 : 790-9.

[111] McMahon M, Gilad A, Zhou J, et al. Quantifying exchange rates in chemical exchange saturation transfer agents using the saturation time and saturation power dependencies of the magnetization transfer effect on the magnetic resonance imaging signal (QUEST and QUESP): $\mathrm{Ph}$ calibration for poly-L-lysine and a starburst dendrimer. Magn Reson Med 2006; 55: 836-47.

[112] Sun PZ. Simplified and scalable numerical solution for describing multi-pool chemical exchange saturation transfer (CEST) MRI contrast. J Magn Reson 2010; 205: 235-41.

[113] Hossmann KA. Viability thresholds and the penumbra of focal ischemia. Ann Neurol 1994; 36: 557-65.

[114] Weinstein PR, Hong S, Sharp FR. Molecular Identification of the Ischemic Penumbra. Stroke 2004; 35: 2666-70.

[115] Simon R, Xiong Z. Acidotoxicity in brain ischaemia. Biochem Soc Trans 2006; 34: 1356-61.

[116] Sun PZ, Zhou J, Huang J, van Zijl P. Simplified Quantitative Description of Amide Proton Transfer (APT) Imaging During Acute Ischemia. Magn Reson Med 2007; 57: 405-10.

[117] Sun PZ, Zhou J, Sun W, Huang J, van Zijl PC. Detection of the ischemic penumbra using pH-weighted MRI. J Cereb Blood Flow Metab 2007; 27: 1129-36.

[118] Jokivarsi KT, Gröhn HI, Gröhn OH, Kauppinen RA. Proton transfer ratio, lactate, and intracellular $\mathrm{pH}$ in acute cerebral ischemia. Magn Reson Med 2007; 57: 647-53.

[119] Pekar J, Jezzard P, Roberts DA, et al. Perfusion imaging with compensation for asymmetric magnetization transfer effects. Magn Reson Med 1996; 35: 70-9.
[120] Mougin OE, Coxon RC, Pitiot A, Gowland PA. Magnetization transfer phenomenon in the human brain at $7 \mathrm{~T}$. NeuroImage 2010; 49: 272-81.

[121] Sun PZ, Benner T, Copen W, Sorensen A. Early experience of translating $\mathrm{pH}$-weighted MRI to image human subjects at 3 Tesla. Stroke 2010; 41: S147-S51.

[122] Sicard KM, Henninger N, Fisher M, Duong TQ, Ferris CF. LongTerm Changes of Functional MRI-Based Brain Function, Behavioral Status, and Histopathology After Transient Focal Cerebral Ischemia in Rats. Stroke 2006; 37: 2593-600.

[123] Bisschops RHC, Kappelle LJ, Mali WPTM, van der Grond J. Hemodynamic and Metabolic Changes in Transient Ischemic Attack Patients: A Magnetic Resonance Angiography and $1 \mathrm{H}-$ Magnetic Resonance Spectroscopy Study Performed Within 3 Days of Onset of a Transient Ischemic Attack. Stroke 2002; 33: 110-5.

[124] Karaszewski B, Wardlaw JM, Marshall I, et al. Early brain temperature elevation and anaerobic metabolism in human acute ischaemic stroke. Brain 2009; 132: 955-64.

[125] Dixon TW, Ren J, Lubag A, J. M. , et al. A concentrationindependent method to measure exchange rates in PARACEST agents. Magn Reson Med 2010; 63: 625-32.

[126] Thulborn KR, Davis D, Snyder J, Yonas H, Kassam A. Sodium MR Imaging of Acute and Subacute Stroke for Assessment of Tissue Viability. Neuroimaging Clin N Am 2005; 15: 639-53.

[127] Pirttilä T-R, Kauppinen R. Recovery of intracellular $\mathrm{pH}$ in cortical brain slices following anoxia studied by nuclear magnetic resonance spectroscopy: role of lactate removal, extracellular sodium and sodium/hydrogen exchange. Neuroscience 1992; 47: 155-64.

[128] Lipton P. Ischemic Cell Death in Brain Neurons. Physiol Rev 1999; 79: 1431-568.

[129] Lin S-P, Song S-K, Miller JP, Ackerman JJH, Neil JJ. Direct, Longitudinal Comparison of $1 \mathrm{H}$ and $23 \mathrm{Na}$ MRI After Transient Focal Cerebral Ischemia. Stroke 2001; 32: 925-32.

[130] Boada F, Gillen J, Shen G, Chang S, Thulborn K. Fast three dimensional sodium imaging. Magn Reson Med 1997; 37: 706-15.

[131] Wang Y, Hu W, Perez-Trepichio AD, et al. Brain Tissue Sodium Is a Ticking Clock Telling Time After Arterial Occlusion in Rat Focal Cerebral Ischemia Editorial Comment. Stroke 2000; 31: 1386-92.

[132] Jones SC, Kharlamov A, Yanovski B, et al. Stroke onset time using sodium MRI in rat focal cerebral ischemia. Stroke 2006; 37: 883-8.

[133] Knight RA, Dereski MO, Helpern JA, Ordidge RJ, Chopp M. Magnetic-resonance-imaging assessment of evoluing focal cerebral-ischemia--comparison with histopathology in rats. Stroke 1994; 25: 1252-61.

[134] Jokivarsi KT, Hiltunen Y, Tuunanen PI, Kauppinen RA, Grohn OHJ. Correlating tissue outcome with quantitative multiparametric MRI of acute cerebral ischemia in rats. J Cereb Blood Flow Metab 2009; 30: 415-27.

[135] Carano R, Takano K, Helmer K, et al. Determination of focal ischemic lesion volume in the rat brain using multispectral analysis. J Magn Reson Imaging 1998; 8: 1266-78.

[136] Jacobs MA, Knight RA, Soltanian-Zadeh H, et al. Unsupervised segmentation of multiparameter MRI in experimental cerebral ischemia with comparison to T2, diffusion, and ADC MRI parameters and histopathological validation. J Magn Reson Imaging 2000; 11: 425-37.

[137] Soltanian-Zadeh H, Windham J, Robbins L. Semi-supervised segmentation of MRI stroke studies. Proc SPIE 1997; 3034: 43748 .

[138] Jacobs MA, Mitsias P, Soltanian-Zadeh H, et al. Multiparametric MRI tissue characterization in clinical stroke with correlation to clinical outcome: part 2. Stroke 2001; 32: 950-7.

[139] Jacobs MA, Zhang ZG, Knight RA, et al. A model for multiparametric mri tissue characterization in experimental cerebral ischemia with histological validation in rat: part 1 . Stroke 2001; 32: 943-9.

[140] Mitsias PD, Jacobs MA, Hammoud R, et al. Multiparametric MRI ISODATA ischemic lesion analysis: correlation with the clinical neurological deficit and single-parameter MRI techniques. Stroke 2002; 33: 2839-44.

[141] Ding G, Jiang Q, Zhang L, et al. Multiparametric ISODATA analysis of embolic stroke and rt-PA intervention in rat. J Neurol Sci 2004; 223: 135-43. 
[142] Nagesh V, Welch KM, Windham JP, et al. Time course of ADCw changes in ischemic stroke: beyond the human eye! Stroke 1998; 29: $1778-82$.

[143] Shen Q, Ren H, Fisher M, Duong TQ. Statistical prediction of tissue fate in acute ischemic brain injury. J Cereb Blood Flow Metab 2005; 25: 1336-45.
[144] Shen Q, Duong TQ. Quantitative prediction of ischemic stroke tissue fate. NMR Biomed 2008; 21: 839-48.

[145] Huang S, Shen Q, Duong TQ. Artificial neural network prediction of ischemic tissue fate in acute stroke imaging. J Cereb Blood Flow Metab 2010; 30: 1661-70.

(C) Cheung et al.; Licensee Bentham Open.

This is an open access article licensed under the terms of the Creative Commons Attribution Non-Commercial License (http://creativecommons.org/licenses/by-nc/3.0/) which permits unrestricted, non-commercial use, distribution and reproduction in any medium, provided the work is properly cited. 